\title{
Effects of probucol on atherosclerotic plaque and soluble thrombomodulin in patients with coronary heart disease
}

\author{
DONGHAI LIU ${ }^{1}$, GUOPING YANG ${ }^{2}$, XUEBIN ZHAO $^{1}$ and HUANZHI YANG ${ }^{3}$ \\ ${ }^{1}$ Department of Emergency, The First People's Hospital of Jining, Jining, Shandong 272011; \\ ${ }^{2}$ Department of Cardiology, Zibo Zhoucun People's Hospital, Zibo, Shandong 255000; \\ ${ }^{3}$ Department of Neurology, Binzhou City Central Hospital, Binzhou, Shandong 251700, P.R. China
}

Received March 3, 2018; Accepted May 30, 2018

DOI: $10.3892 / \mathrm{etm} .2018 .6264$

\begin{abstract}
This study explored the effects of probucol on atherosclerotic plaques and soluble thrombomodulin in patients with coronary heart disease (CHD). Five hundred and eighty-three patients with CHD who were admitted to Jining First People's Hospital from February 2013 to February 2014. A total of 300 of them received conventional treatment, and were assigned to the control group, while the remaining 283 patients were treated with probucol in addition to the conventional treatment, and were assigned to the observation group. A retrospective analysis was performed on the total cholesterol levels, atherosclerotic plaque sizes, and soluble thrombomodulin levels. Probucol was administered at a dose of $500 \mathrm{mg}$ twice a day for a period of 16 weeks. The total cholesterol level decreased gradually over time during the treatment. After 8 weeks of treatment, the total cholesterol level in the observation group was lower than that in the control group $(\mathrm{P}<0.05)$. After 8 weeks of treatment, the atherosclerotic plaque area in the observation group decreased compared with that before treatment $(\mathrm{P}<0.05)$. After 8 and 16 weeks of treatment, the plaque area in the observation group was smaller than that in the control group $(\mathrm{P}<0.05)$. The soluble thrombomodulin level at any time-point after treatment was lower than that before treatment in both groups $(\mathrm{P}<0.05)$. At the same time-point, the level in the observation group was lower than that in the control group $(\mathrm{P}<0.05)$. The total cholesterol and soluble thrombomodulin levels were positively correlated with the atherosclerotic plaque area $(\mathrm{r}=0.841, \mathrm{P}=0.001$; $\mathrm{r}=0.725, \mathrm{P}=0.008$ ). When patients with $\mathrm{CHD}$ were treated with probucol in addition to the conventional treatment, a reduction of the atherosclerotic plaque area, as well as a decrease of both the total cholesterol and soluble thrombomodulin levels, was
\end{abstract}

Correspondence to: Dr Xuebin Zhao, Department of Emergency, The First People's Hospital of Jining, 6 Jiankang Road, Jining, Shandong 272011, P.R. China

E-mail: bv38nq@163.com

Key words: probucol, coronary heart disease, atherosclerotic plaque, soluble thrombomodulin, total cholesterol observed. Overall, patients with CHD experienced improved symptoms following treatment with probucol.

\section{Introduction}

Coronary atherosclerotic heart disease, also known as coronary heart disease (CHD), is a very common cardiovascular disorder. It is one of the major causes leading to cardiac dysfunction in patients, and is the leading cause of death for both men and women worldwide $(1,2)$. It was recently reported that CHD incidence in developed countries has declined, while in developing countries has increased, which may be due to changes in diet as a result of economic development (3). High-fat diet and low cholesterol consumption play an important role in the pathogenesis of CHD (4). According to a WHO report published in 2011, the incidence of CHD in China was approximately $8 \%$, and the mortality rate was the second in the world (5).

Cholesterol level is an important risk factor for patients with CHD, while the soluble thrombomodulin level can predict plaque stability in patients with CHD. Probucol demonstrated satisfactory therapeutic effects in protecting against atherosclerosis, stabilizing atherosclerotic plaques, preventing coronary artery restenosis, and lowering lipids (6,7). Studies have shown that probucol was effective in the dissolution of atherosclerotic plaques, as well as the reduction of soluble thrombomodulin level, in patients with atherosclerosis $(8,9)$. In this study, 300 out of 583 patients with CHD who were admitted to Jining First People's Hospital (Jining, China) from February 2013 to February 2014 received conventional treatment, while the remaining 283 were treated with probucol in addition to the conventional treatment. A retrospective analysis was performed on the total cholesterol levels, atherosclerotic plaque sizes, and soluble thrombomodulin levels before and after treatment in both groups. The data were compared in order to explore the efficacy of probucol in CHD patients.

\section{Patients and methods}

Subjects. A total of 583 patients with CHD, admitted to Jining First People's Hospital (Jining, China) from February 2013 to February 2014, were recruited into this study. Their conditions were confirmed according to the diagnostic criteria for CHD 
published by WHO in 2012 (10). Of them, 300 patients received conventional treatment only, and were assigned to the control group. The remaining 283 patients were treated with probucol in addition to the conventional treatment, and were assigned to the observation group. Patients who also had the following conditions were excluded: unstable coronary artery disease, intermittent myocardial infarction, acute myocardial infarction, infectious disease, severe cardiac insufficiency, cancer, grade III hypertension, liver and kidney failure, and mental or learning disabilities. Patients who had incomplete clinical data were excluded as well. This study was approved by the Ethics Committee of Jining First People's Hospital (Jining, China), and patients or their families signed an informed consent.

Methods. In conventional treatment, the following drugs were administered: antiplatelet agents, nitrate vasodilators, angiotensin-converting enzyme inhibitors, and $\alpha$ receptor blockers. For patients in the observation group, probucol was given at a dose of $500 \mathrm{mg}$ twice a day for 16 weeks in addition to the conventional treatment. Probucol was manufactured by Qilu Pharmaceutical Co., Ltd. (Jinan, China) with SFDA approval no. H10980054.

Observed indicators. Peripheral blood samples were collected, and atherosclerotic plaque images were obtained through ultrasound imaging. The total cholesterol level, atherosclerotic plaque area, and soluble thrombomodulin level were measured before treatment as well as 4,8 and 16 weeks after treatment. The obtained data were compared between the two groups to determine the correlation of the total cholesterol and soluble thrombomodulin levels with atherosclerotic plaque area. Cholesterol test kits (DAOS method) and human soluble thrombomodulin (sTM) ELISA kits were purchased from Shanghai Yanhui Biotechnology Co., Ltd. (Shanghai, China) and Beijing BioDee Biotechnology Co., Ltd. (Beijing, China), respectively. The atherosclerotic plaque area was measured using a Philips iE33 color Doppler ultrasound system (Eindhoven, Netherlands).

Statistical analysis. SPSS 19.0 statistics software from Asia Analytics (formerly SPSS China) was used for data processing. The $\chi^{2}$ test was applied in comparison of rates. Measurement data are expressed as mean \pm standard deviation. The non-parametric K-S test was used for comparison between the two groups. A logistic association analysis was performed to estimate correlations of the atherosclerotic plaque area with the total cholesterol and soluble thrombomodulin levels. $\mathrm{P}<0.05$ was considered to indicate a statistically significant difference.

\section{Results}

Clinical data. Of the 583 patients with CHD, 283 were assigned to the observation group, including 169 males and 114 females with an average age of $51.6 \pm 22.3$ years. The remaining 300 patients were assigned to the control group, including 172 males and 128 females with an average age of $49.7 \pm 18.6$ years. There were no significant differences in the basic data between the two groups such as sex, body weight, age, and number of coronary artery lesions $(\mathrm{P}>0.05)$. Within
Table I. Basic clinical data of patients in the two groups.

\begin{tabular}{|c|c|c|c|c|}
\hline Items & $\begin{array}{l}\text { Control } \\
\text { group }\end{array}$ & $\begin{array}{l}\text { Observation } \\
\text { group }\end{array}$ & $t / \chi^{2}$ & P-value \\
\hline No. of patients & 300 & 283 & & \\
\hline \multicolumn{5}{|l|}{ Sex } \\
\hline Male & 172 & 169 & 0.762 & 0.519 \\
\hline Female & 128 & 114 & & \\
\hline Age (years) & $49.7 \pm 18.6$ & $51.6 \pm 22.3$ & 0.547 & 0.744 \\
\hline \multicolumn{5}{|l|}{$\begin{array}{l}\text { Coronary artery } \\
\text { lesions (n, \%) }\end{array}$} \\
\hline Single & $91(30.33)$ & $100(35.34)$ & 0.594 & 0.625 \\
\hline Multiple $^{\mathrm{a}}$ & $209(69.67)$ & $183(64.66)$ & & \\
\hline \multicolumn{5}{|c|}{$\begin{array}{l}\text { Body weight }(\mathrm{kg}) \\
(\mathrm{n}, \%)\end{array}$} \\
\hline$\geq 50^{\mathrm{b}}$ & $214(71.33)$ & $182(64.31)$ & 0.175 & 0.969 \\
\hline$<50$ & $86(28.67)$ & $101(35.69)$ & & \\
\hline \multicolumn{5}{|l|}{$\begin{array}{l}\text { Residence area, } \\
(\mathrm{n}, \%)\end{array}$} \\
\hline Urban $^{\mathrm{c}}$ & $181(60.33)$ & $172(60.78)$ & 0.976 & 0.381 \\
\hline Rural & 119 (39.67) & $111(39.22)$ & & \\
\hline \multicolumn{5}{|l|}{$\begin{array}{l}\text { Physical exercise, } \\
(\mathrm{n}, \%)\end{array}$} \\
\hline Yes & $103(34.33)$ & $102(36.04)$ & 1.147 & 0.311 \\
\hline $\mathrm{No}^{\mathrm{d}}$ & $197(65.67)$ & $181(63.96)$ & & \\
\hline
\end{tabular}

${ }^{\mathrm{a}} \mathrm{P}=0.025$ and 0.025 , respectively, for comparison of the number of patients with multiple coronary artery lesions and the number of patients with single coronary artery lesion within the control and observation groups; ${ }^{\mathrm{b}} \mathrm{P}=0.013$ and 0.031 , respectively, for comparison of the number of patients with weight $\geq 50 \mathrm{~kg}$ and number of patients with weight $<50 \mathrm{~kg}$ within the control and observation groups; ${ }^{c} \mathrm{P}=0.032$ and 0.032 , respectively, for comparison of the number of patients living in urban areas and the number of patients living in rural areas within the control and observation groups; ${ }^{\mathrm{d}} \mathrm{P}=0.029$ and 0.030 , respectively, for comparison of the number of patients with physical exercise habit and the number of patients without physical exercise habit within the control and observation groups.

the same group, the number of patients with multiple coronary artery lesions was higher than that of patients with single coronary artery lesion $(\mathrm{P}<0.05)$, and the number of patients with weight $\geq 50 \mathrm{~kg}$ was greater than that of patients with weight $<50 \mathrm{~kg}(\mathrm{P}<0.05)$. Most patients in the two groups lived in urban areas $(\mathrm{P}<0.05)$, and rarely had routine physical exercise $(\mathrm{P}<0.05)$. The details are listed in Table I.

Total cholesterol level after treatment. The total cholesterol level was monitored during treatment for all patients, which decreased gradually over time in both groups. After 4 weeks of treatment, small improvements in the total cholesterol level were observed in both groups $(\mathrm{P}>0.05)$, but there was no difference between the two groups $(\mathrm{P}>0.05)$. After 8 weeks of treatment, further improvements in the total cholesterol level were observed in both groups $(\mathrm{P}<0.05)$, and the level in the observation group was much lower than that in the control group $(\mathrm{P}<0.05)$. After 16 weeks of treatment, significant improvements in the total cholesterol level were observed in both groups $(\mathrm{P}<0.05)$, whereas there was no significant 
Table II. Total cholesterol level after treatment (mmol/l).

\begin{tabular}{lcccc}
\hline Time-points & $\begin{array}{c}\text { Control } \\
\text { group }\end{array}$ & $\begin{array}{c}\text { Observation } \\
\text { group }\end{array}$ & $\mathrm{t}$ & P-value \\
\hline $\begin{array}{l}\text { Before } \\
\text { treatment }\end{array}$ & $5.06 \pm 0.88$ & $5.13 \pm 0.97$ & 0.242 & 0.926 \\
$\begin{array}{l}\text { After treatment, } \\
4 \text { weeks }\end{array}$ & $4.31 \pm 0.39$ & $4.58 \pm 0.47$ & 0.413 & 0.843 \\
$\begin{array}{l}\text { After treatment, } \\
8 \text { weeks }\end{array}$ & $3.59 \pm 0.38^{\mathrm{a}}$ & $2.64 \pm 0.22^{\mathrm{d}}$ & 2.339 & 0.034 \\
$\begin{array}{l}\text { After treatment, } \\
16 \text { weeks }\end{array}$ & $2.56 \pm 0.24^{\mathrm{b}, \mathrm{c}}$ & $2.33 \pm 0.17^{\mathrm{e}}$ & 0.641 & 0.672 \\
& & & &
\end{tabular}

${ }^{\mathrm{a}} \mathrm{P}<0.05$, in comparison with the level before treatment; ${ }^{\mathrm{b}} \mathrm{P}<0.05$, in comparison with the level before treatment; ${ }^{~} \mathrm{P}<0.05$, in comparison with the level 8 weeks after treatment; ${ }^{d} \mathrm{P}<0.05$, in comparison with the level before treatment; ${ }^{\mathrm{e}} \mathrm{P}<0.05$, in comparison with the level before treatment.

Table III. Atherosclerotic plaque area after treatment $\left(\mathrm{mm}^{2}\right)$.

\begin{tabular}{lcccc}
\hline Time-points & $\begin{array}{c}\text { Control } \\
\text { group }\end{array}$ & $\begin{array}{c}\text { Observation } \\
\text { group }\end{array}$ & $\mathrm{t}$ & P-value \\
\hline $\begin{array}{l}\text { Before } \\
\text { treatment }\end{array}$ & $4.05 \pm 0.83$ & $4.01 \pm 0.81$ & 0.213 & 0.943 \\
$\begin{array}{l}\text { After treatment, } \\
4 \text { weeks }\end{array}$ & $3.87 \pm 0.73$ & $3.84 \pm 0.59$ & 0.147 & 0.985 \\
$\begin{array}{l}\text { After treatment, } \\
8 \text { weeks }\end{array}$ & $3.64 \pm 0.41$ & $3.29 \pm 0.33^{\mathrm{a}}$ & 2.386 & 0.031 \\
$\begin{array}{l}\text { After treatment, } \\
16 \text { weeks }\end{array}$ & $3.62 \pm 0.45$ & $3.15 \pm 0.28^{\mathrm{b}}$ & 2.426 & 0.029 \\
\hline
\end{tabular}

${ }^{\mathrm{a}} \mathrm{P}<0.05$, in comparison with the area before treatment; ${ }^{\mathrm{b}} \mathrm{P}<0.05$, in comparison with the area before treatment.

difference between the two groups $(P>0.05)$. The data indicated that the conventional treatment in combination with probucol reduced the total cholesterol level of patients with CHD in a shorter time (Table II).

Atherosclerotic plaque area after treatment. After 4 weeks of treatment, small decreases in plaque area were observed in both groups $(\mathrm{P}>0.05)$, but there was no difference between the two groups. After 8 and 16 weeks of treatment, the plaque areas in the observation group were all significantly smaller than those in the control group $(\mathrm{P}<0.05)$. Overall, the plaque area gradually decreased over time during treatment in both groups. After 8 and 16 weeks of treatment, the plaque area decreased significantly in the observation group $(\mathrm{P}<0.05)$, whereas the plaque area decreased slightly at all time-points in the control group $(\mathrm{P}>0.05)$. The data suggested that the conventional treatment in combination with probucol was much more effective in reducing plaque area than the conventional treatment only (Table III).
Table IV. Soluble thrombomodulin level after treatment $(\mu \mathrm{g} / \mathrm{l})$.

\begin{tabular}{lcccc}
\hline Time-points & $\begin{array}{c}\text { Control } \\
\text { group }\end{array}$ & $\begin{array}{c}\text { Observation } \\
\text { group }\end{array}$ & t & P-value \\
\hline $\begin{array}{l}\text { Before } \\
\text { treatment }\end{array}$ & $68.7 \pm 25.6$ & $69.1 \pm 24.7$ & 0.294 & 0.914 \\
$\begin{array}{l}\text { After treatment, } \\
4 \text { weeks }\end{array}$ & $56.4 \pm 21.7^{\mathrm{a}}$ & $47.7 \pm 19.5^{\mathrm{d}}$ & 2.328 & 0.036 \\
$\begin{array}{l}\text { After treatment, } \\
8 \text { weeks }\end{array}$ & $48.1 \pm 18.9^{\mathrm{b}}$ & $34.5 \pm 16.8^{\mathrm{e}}$ & 2.349 & 0.032 \\
$\begin{array}{l}\text { After treatment, } \\
16 \text { weeks }\end{array}$ & $26.7 \pm 8.6^{\mathrm{c}}$ & $17.4 \pm 7.6^{\mathrm{f}}$ & 2.479 & 0.025 \\
& & & & \\
\end{tabular}

${ }^{\mathrm{a}} \mathrm{P}<0.05$, in comparison with the level before treatment; ${ }^{b} \mathrm{P}<0.05$, in comparison with the levels before treatment and 4 weeks after treatment; ${ }^{\mathrm{P}} \mathrm{P}<0.05$, in comparison with the levels before treatment and 8 weeks after treatment; ${ }^{\mathrm{d}} \mathrm{P}<0.05$, in comparison with the level before treatment; ${ }^{\mathrm{e}} \mathrm{P}<0.05$, in comparison with the levels before treatment and 4 weeks after treatment; ${ }^{\mathrm{f}} \mathrm{P}<0.05$, in comparison with the levels before treatment and 8 weeks after treatment.

Soluble thrombomodulin level after treatment. Before treatment, there was no difference in soluble thrombomodulin level between the two groups ( $\mathrm{P}>0.05)$. Over time during treatment, the level decreased in both groups. The level at each time-point after treatment was significantly lower than that before treatment $(\mathrm{P}<0.05)$. At the same time-point after treatment, the soluble thrombomodulin level in the observation group was much lower than that in the control group $(\mathrm{P}<0.05)$. The data indicated that the conventional treatment in combination with probucol further reduced the soluble thrombomodulin level, compared with the conventional treatment only (Table IV).

Correlation analysis of atherosclerotic plaque area with total cholesterol and soluble thrombomodulin. Total cholesterol and soluble thrombomodulin levels were all positively correlated with the atherosclerotic plaque area $(\mathrm{r}=0.841, \mathrm{P}=0.001$; $\mathrm{r}=0.725, \mathrm{P}=0.008$ ).

\section{Discussion}

CHD related morbidity and mortality are high worldwide, indicating CHD is a serious challenge to human health. Atherosclerosis is the leading cause of CHD. Reducing atherosclerotic plaque area, lowering cholesterol level in blood, and thinning the inner lining of coronary artery are important treatment strategies for improving the survival of CHD patients $(11,12)$. Soluble thrombomodulin is a biomarker of vascular endothelial damage. Lowering its level in blood can protect endothelial function and prevent thrombosis (13).

In this study, clinical data of $583 \mathrm{CHD}$ patients treated from February 2013 to February 2014 were collected and retrospectively analyzed to explore the effects of probucol and the conventional treatment on atherosclerotic plaque and soluble thrombomodulin level. The results suggested that probucol promoted the shrinking of atherosclerotic plaque. After 8 weeks of treatment, patients in the observation group 
experienced significant plaque shrinkage $(\mathrm{P}<0.05)$, whereas limited plaque shrinkage was observed in patients in the control group $(\mathrm{P}>0.05)$. Our findings were in accordance with those reported in literature where $\mathrm{Li}$ et al reported that probucol alleviated progression of atherosclerotic lesion and the increase of plaque area by modulating NHE1 (14). Reducing the plaque area in a shorter time by administration of probucol in addition to the conventional treatment was important for the prevention of thrombosis in patients.

The total cholesterol level in blood was also monitored for all CHD patients. After 4 weeks of treatment, small improvements in the total cholesterol level were observed in both groups $(\mathrm{P}>0.05)$. After 8 weeks of treatment, the level in the observation group was much lower than that in the control group $(\mathrm{P}<0.05)$. Whereas after 16 weeks of treatment, the total cholesterol in both groups decreased to a comparable level, and there was no significant difference between them ( $P>0.05)$. A faster reduction of the total cholesterol level by additional probucol administration may be beneficial to the atherosclerotic plaque shrinkage, because the total cholesterol level is an important risk factor for atherosclerosis (15). Correlation analysis also indicated that the total cholesterol level and atherosclerotic plaque area were positively correlated $(\mathrm{r}=0.841, \mathrm{P}=0.001)$. Zhu et al reported that probucol effectively reduced plasma total cholesterol and high-density lipoprotein cholesterol levels, and alleviated atherosclerosis (16). Probucol was also reported to have a positive effect on stabilizing atherosclerotic plaque in patients with hypercholesterolemia (17).

In this study, the soluble thrombomodulin level in blood was measured as well. The level decreased in both groups over time during treatment. At the same time-point after treatment, the soluble thrombomodulin level in the observation group was much lower than that in the control group $(\mathrm{P}<0.05)$. This indicated that additional probucol in the conventional treatment can improve the soluble thrombomodulin level more efficiently. Thrombomodulin is an endothelial cell surface glycoprotein that plays an important role in the vascular homeostasis. It is a determinant of thrombosis in the inner lining of blood vessels. Improving thrombomodulin level in blood was directly related to the alleviation of symptoms of patients with atherosclerosis, and played an important role in enhancing anticoagulation in patients and preventing thrombosis $(18,19)$. Correlation analysis in this study showed that a positive correlation between the plasma thrombomodulin level and atherosclerotic plaque area $(\mathrm{r}=0.725, \mathrm{P}=0.008)$. This is consistent with the findings of Hong et al who reported that probucol reduced the soluble thrombomodulin level in blood, and may improve the endothelial function of rabbits with hypercholesterolemia (20).

Based on the findings in this study, probucol may exert its therapeutic effect on CHD by downregulation of the total cholesterol and thrombomodulin in blood, as well as reduction of the atherosclerotic plaque area. However, in this study, the collected patients' data are not enough to completely analyze the incidence of complications in patients after using probucol, so it is limited to evaluate the safety of probucol. The preventive effects of probucol against atherosclerosis in patients with CHD have been previously reported. Yamashita et al (21) reported the safety of probucol in long-term treatment. However, in spite of these findings, we still aim to investigate this further.
In conclusion, when patients with CHD were treated with probucol in addition to the conventional treatment, a reduction of atherosclerotic plaque area, as well as a decrease of both the total cholesterol and soluble thrombomodulin levels, was observed. Overall, patients with CHD experienced improved symptoms following treatment with probucol.

\section{Acknowledgements}

Not applicable.

\section{Funding}

No funding was received.

\section{Availability of data and materials}

The datasets used and/or analyzed during the present study are available from the corresponding author on reasonable request.

\section{Authors' contributions}

DL, GY and XZ contributed to the concept and design of the study. HY performed the experiments and analyzed the data. $\mathrm{XZ}$ wrote and finalized the manuscript. All authors have read and approved the final manuscript.

\section{Ethics approval and consent to participate}

The study was approved by the Ethics Committee of The First People's Hospital of Jining (Jining, China). Patients who participated in this study had complete clinical data. Signed informed consents were obtained from patients or guardians.

\section{Patient consent for publication}

Not applicable.

\section{Competing interests}

The authors declare that they have no competing interests.

\section{References}

1. Cooper CL and Marshall J: Occupational sources of stress: A review of the literature relating to coronary heart disease and mental ill health. In: From Stress to Wellbeing. Cooper CL (ed). Vol I. Palgrave Macmillan, UK, pp3-23, 2013.

2. Dawber TR, Moore FE and Mann GV: Coronary heart disease in the Framingham study. Am J Public Health Nations Health 47: 4-24, 1957.

3. Canoy D, Cairns BJ, Balkwill A, Wright FL, Khalil A, Beral V, Green J and Reeves G; Million Women Study Collaborators: Hypertension in pregnancy and risk of coronary heart disease and stroke: A prospective study in a large UK cohort. Int J Cardiol 222: 1012-1018, 2016.

4. Nordestgaard BG, Chapman MJ, Humphries SE, Ginsberg HN, Masana L, Descamps OS, Wiklund O, Hegele RA, Raal FJ, Defesche JC, et al; European Atherosclerosis Society Consensus Panel: Familial hypercholesterolaemia is underdiagnosed and undertreated in the general population: guidance for clinicians to prevent coronary heart disease: consensus statement of the European Atherosclerosis Society. Eur Heart J 34: 3478-3490, 2013. 
5. Santulli G: Epidemiology of cardiovascular disease in the 21st century: Updated numbers and updated facts. J Cardiovasc Dis 1: $1-2,2013$.

6. Richard E, von Muhlen D, Barrett-Connor E, Alcaraz J, Davis R and McCarthy JJ: Modification of the effects of estrogen therapy on HDL cholesterol levels by polymorphisms of the HDL-C receptor, SR-BI: The Rancho Bernardo Study. Atherosclerosis 180: 255-262, 2005

7. Yakushiji E, Ayaori M, Nishida T, Shiotani K, Takiguchi S, Nakaya K, Uto-Kondo H, Ogura M, Sasaki M, Yogo M, et al: Probucol-oxidized products, spiroquinone and diphenoquinone, promote reverse cholesterol transport in mice. Arterioscler Thromb Vasc Biol 36: 591-597, 2016.

8. Artom N, Montecucco F, Dallegri F and Pende A: Carotid atherosclerotic plaque stenosis: The stabilizing role of statins. Eur J Clin Invest 44: 1122-1134, 2014.

9. Yamashita S, Masuda D and Matsuzawa Y: Did we abandon probucol too soon? Curr Opin Lipidol 26: 304-316, 2015.

10. Fu CG, Gao ZY and Wang PL: Study on the diagnostic criteria for coronary heart disease patients of blood stasis syndrome Zhongguo Zhong Xi Yi Jie He Za Zhi 32: 1285-1286, 2012 (In Chinese).

11. Taylor RS, Brown A, Ebrahim S, Jolliffe J, Noorani H, Rees K, Skidmore B, Stone JA, Thompson DR and Oldridge N: Exercise-based rehabilitation for patients with coronary heart disease: Systematic review and meta-analysis of randomized controlled trials. Am J Med 116: 682-692, 2004.

12. Lu Y, Hajifathalian K, Ezzati M, Woodward M, Rimm EB and Danaei G; Global Burden of Metabolic Risk Factors for Chronic Diseases Collaboration (BMI Mediated Effects): Metabolic mediators of the effects of body-mass index, overweight, and obesity on coronary heart disease and stroke: A pooled analysis of 97 prospective cohorts with $1 \bullet 8$ million participants. Lancet 383 : 970-983, 2014

13. Ito T, Kakihana $Y$ and Maruyama I: Thrombomodulin as an intravascular safeguard against inflammatory and thrombotic diseases. Expert Opin Ther Targets 20: 151-158, 2016.

14. Li JF, Chen S, Feng JD, Zhang MY and Liu XX: Probucol via inhibition of NHE1 attenuates LPS-accelerated atherosclerosis and promotes plaque stability in vivo. Exp Mol Pathol 96 250-256, 2014
15. Janoudi A, Shamoun FE, Kalavakunta JK and Abela GS: Cholesterol crystal induced arterial inflammation and destabilization of atherosclerotic plaque. Eur Heart J 37: 1959-1967, 2016.

16. Zhu H, Jin X, Zhao J, Dong Z, Ma X, Xu F, Huang W, Liu G, Zou Y, Wang K, et al: Probucol protects against atherosclerosis through lipid-lowering and suppressing immune maturation of $\mathrm{CD}_{11 \mathrm{c}^{+}}$dendritic cells in STZ-induced diabetic $\mathrm{LDLR}^{-/-}$mice. $\mathrm{J}$ Cardiovasc Pharmacol 65: 620-627, 2015.

17. Li S, Liang J, Niimi M, Bilal Waqar A, Kang D, Koike T, Wang Y, Shiomi M and Fan J: Probucol suppresses macrophage infiltration and MMP expression in atherosclerotic plaques of WHHL rabbits. J Atheroscler Thromb 21: 648-658, 2014.

18. Martin FA, McLoughlin A, Rochfort KD, Davenport C, Murphy RP and Cummins PM: Regulation of thrombomodulin expression and release in human aortic endothelial cells by cyclic strain. PLoS One 9: e108254, 2014.

19. Chen PS, Wang KC, Chao TH, Chung HC, Tseng SY, Luo CY, Shi GY, Wu HL and Li YH: Recombinant thrombomodulin exerts anti-autophagic action in endothelial cells and provides anti-atherosclerosis effect in apolipoprotein E deficient mice. Sci Rep 7: 3284, 2017.

20. Hong SC, Zhao SP, Liu Q and Wu ZH: Effect of the anti-oxidant probucol on soluble thrombomodulin (sTM) in hypercholesterolemic rabbits. Int J Cardiol 123: 180-182, 2008.

21. Yamashita S, Masuda D, Ohama T, Arai H, Bujo H, Kagimura T, Kita T, Matsuzaki M, Saito Y, Fukushima M, et al; PROSPECTIVE Study Group: Rationale and design of the PROSPECTIVE trial: Probucol trial for secondary prevention of atherosclerotic events in patients with prior coronary heart disease. J Atheroscler Thromb 23: 746-756, 2016.

This work is licensed under a Creative Commons Attribution-NonCommercial-NoDerivatives 4.0 International (CC BY-NC-ND 4.0) License. 